\title{
Personalised Learning: The New World Order in Education
}

\author{
Shradha Kanwar \\ NIIT University (India)
}

\begin{abstract}
The exponential growth in the past few decades has influenced the learning process in a huge way. This impact has also been felt across different education verticals. The transition from oral to print to digitization has created a challenge in the field of education and now with techno centric rich media emerging as the need of the hour- the attention towards innovative practices in education has further accentuated. The learning environment demands more from its stake holders who need to optimise on the new forces of learning. This study builds on existing research to pre-empt the futuristic challenges and inventive mechanisms; redefining the purpose of education along with suggesting techniques to repurpose curriculum, instructional methodologies and assessment strategies to nurture personal learning spaces. An attempt is made to evaluate the criticality of technology in generating rich forms of multiple media to combat varied learning styles and intelligences. The paper delineates the importance of new learning standards in defining the future world order and analyses the merits of transforming the classrooms from programmed learning to application oriented learning with specific personalised outcomes.
\end{abstract}

\section{Introduction}

The future demands resourceful ideas. Prognosticating this, the thrust now is on novel ways of creating, handling and delivering knowledge that will make learning not just an event but a lifelong experience. The new era unravels an elusive knowledge world where the visionary educators who are able to effectively blend the dynamism of the future with the might of the present shall succeed. Fenstermacher and Soltis suggest that there are three possible approaches to teaching: execution, facilitating and liberating.[1] In the era of changing demographics, globalization and technological development the approaches to teaching are also changing substantially.
This paper advocates this futuristic aspect of education that would lead to a new dimension of personalised learning in the future - vis a vis real pedagogical and cognitive changes from curriculum planning to innovative methodologies and effective assessment strategy- that could prove to be the defining factor in the future.

\section{Personalised learning}

Information access has resulted in saturated, innovation hungry individuals and to combat their appetite for knowledge has become a challenging task for teachers. Jung and Rha considered learnercentred, interactive and experiential e-learning and proposed that extended learning space was needed for three essential learning activities: acquisition, application, and construction.[2] Where knowledge acquisition was the primary aim of the conventional education system, the change towards application oriented teaching is going to be the hallmark of the future. Learners shall no longer be confined to the boundaries of space and time. Learning shall be an ongoing process, unbridled and engaging.

Anticipating these changes, many institutes are founding a complete experiential learning ethos where the learners have the independence to design their own curriculum and assessment model. Constructivist learner centric mode of transmitting knowledge is becoming extremely popular in institutes who are innovating their educational strategies. From mass learning, the focus is gradually shifting to a more personalized learning environment that promotes individual capability and competence.

Research on personalised learning highlights that adequate change is needed in intent, strategy and planning of action oriented, real time learning following which- the future beholds a great opportunity in attuning productive pedagogical outcomes. The hallmark of learning in the new world order is a customised environment which nurtures the potential of each and every learner effectively and efficiently. This is a dramatic shift towards personalised learning. For instance, visual learners would benefit hugely from a simple static stimulus that makes them see and assimilate information 
whereas kinesthetic learners would require a certain animation in the visual stimulus in addition. Each individual is a unique case and therefore needs a unique personalized environment that can target areas of improvement and build on the strengths of each individual. Where one learner might be good in numerical skills and the other better in literary skills, the learning environment today is more adapted to suit collective needs rather than recognize individual efforts and aspirations. Therefore, the need of a more versatile teaching learning process that not just educates but also has an impact on the heart and mind of learners.

\section{Learners' response to changes}

The traditionalist stance in education is based on conforming to the standard principles of learning and any deviation from this set path is bound to create an emotional upheaval. This restrictive approach daunts independent thinking and the curiosity to learn. The true meaning of learning gets lost in between the rigmarole of rote memorization and learners get completely disoriented about the real purpose of learning. Most of these aberrations in our education exist because of inertia in our thought process in accepting change and the lack of initiative in combating change.

The first step in creating an alternative education system begins from a change in the curriculum, which being the centripetal force drives the educational process. Curriculum is the structured set of courses that is offered at a certain grade to ensure the attainment of specific learning outcomes. Curriculum does not refer to the archives of information but the opening of new vistas in knowledge transfer. It is an all inclusive expanse that makes the journey of learning an enriching one. The new education vista promulgates that learners shall be more independent and benefitted from a constructivist and collaborative learning environment. The curriculum in the $21^{\text {st }}$ century should therefore create curiosity that will eventually turn into responsibility. Therefore, there is a dire need to rethink the curriculum, by giving it a more integrative and action oriented approach. This would mean an amalgamation of different disciplines and an interdisciplinary thematic approach towards preparing students for the relevant and rigorous life. Marc Tucker and Judy Codding recommend "a thinking curriculum - one that provides a deep understanding of the subject and the ability to apply that understanding to the complex, real-world problems that the student will face as an adult.” [3]

We carry with us a legacy of the past; we also carry with us a baggage of the past that sometimes restricts our penchant to innovate. The pre set curriculum standards today essentially revolve around the concept of giving and receiving information without any room for innovation. Freire characterises this as the 'banking' concept of education, in which the scope of action allowed to the students extends only as far as receiving, filing and storing the deposits. [4] A significant question looms large, have we attempted to satisfy the erudition instinct in today's learner or we still regressive in realising the impact of change? From the design of curriculum to pedagogy there is so much memory of the past that disallows the acquisition of new knowledge. Therefore, the prevailing and accepted learning skills are not very significant in today's dynamic world because the purpose of education is no longer just to inform but to transform. David Perkins proposes that thinking skills be taught as a "meta-curriculum" intertwined with traditional core subjects. [5]

The design of education that perpetuated memorizing voluminous information and passing standardized stereotyped tests has become obsolete. Alvin Toffler states, "The illiterate of the 21st century will not be those who cannot read and write, but those who cannot learn, unlearn, and relearn. [6] This will only be possible with a continual evolving source of ideas and innovation. Thus in order to move towards a progressive future it is imperative to break the shackles of the past and foster a new future.

\section{Memory Vs Engagement}

The thrust in education today still lies in the ability of students to memorise and produce structured information. This regurgitation of information does not add any value to knowledge but just manages to produce a generation of average literates. Although, the new school of thought strongly advocates the need to dissolve the memory centred learning approach, the curriculum does not offer enough space to practice the same in conventional class rooms. Vrasidas and Glass (2002), Nichols (2003), and Dabbagh (2005) and others suggest that we need new theories of e-education in accordance with the changes in learning orientations and advent of new digital technologies.[7]

Academic credibility needs time to develop and this is possible by inculcating the right learning ethos in sync with changing times. Educators should not restrict themselves to the memory focused style of teaching but should be more open minded, visionary and articulate. The focus should be on integrating problem solving skills and actualizing the potential of every learner by breaking the silos of mere recall.

Due consideration needs to be given to critical thinking and collaborative transaction of knowledge in the curriculum. Instruction should be based on the competencies of the globalised world, on the new century skills and on the vigour of technological inputs. The quintessence of education lies in the 
discovery of new knowledge and hence the curriculum needs to enhance this ability in learners by revitalizing their exploratory abilities.

\section{Blended learning}

Every ideation needs to have a sense of design and every innovation needs to be fit for purpose. Although, research strongly advocates the need to incorporate technology in the curriculum framework, it should be delved in with a degree of caution. Technology tools should not be an add-on, but intricately woven into the curriculum fabric. The pervasive digital culture delights learners with its minutiae and reinforces the need to create a curriculum which is techno savvy but at the same time not overwhelming. The information superfluity poses a challenge to the education world, where abundance of information deters the efforts of new learners to experience the eureka moment. The availability of easy information hampers the scholastic temperament to inquire and unravel through the maze of knowledge. Thus wisdom in the digital world gets wrongly denoted with information access and outcome oriented, rather than knowledge insight and process based results. Conventional academic learning needs to exploit technology to the maxim to create curriculum based on high order thinking skills and more challenging content. The blended format provides an opportunity to take care of different skill sets and learning abilities along with ensuring productive outcomes in tandem with global tendencies.

\section{Pedagogical shift}

In this quest for a changed learning environment, it becomes important to define new pathways of learning. Thus, for being effective in the true sense one needs to adapt to excel, not adjust to survive. As Collins says we are "only good in relation to what we can become."[8] Numerous research findings indicate that educators who have been able to realise this reality and engineer their teaching have a more significant impact on their students' learning.

As the education environment becomes more collaborative and technology oriented, the thrust on the teacher's direction becomes less. This adds to the overall responsibility of a teacher who has to realise their new found role and reconstruct their teaching strategy. The principal pedagogical format today remains the lecture method. With latest auspices of change impacting teaching, the usage of power point presentations has become the latest fad that makes teaching a mundane process. This has become so ingrained in the psyche of some educators that they are not able to look beyond this methodology and realise that the quintessence in teaching lies in the environment becoming more dynamic and liberating; in not just using a particular component of teaching but making it truly meaningful. While the impact of ICT on learning achievement is still a matter of debate, a consensus seems to have formed that there is need for more extensive pre-service and in-service teacher training in ICT-based pedagogy. Such pedagogy needs to be founded upon theory. Garrison argues that theoretical frameworks and models are central to the vitality and development of fields of practice.[9] A theoretical model provides the indispensable blueprint that directs an individual and organisation's progress. A proper framework crafts a culture of integrity and a sense of purpose to strengthen collective intellectual capacity, reducing excessive dependence on physical presence of the teacher and therefore obliterating the people centric constraint.

Most of the innovation that is evident in today's educational environment seems a result of individual keenness and enthusiasm or a forced sense of newness by the organisations. What has to be inculcated is a true spirit of joy and innovation in incubating change. Stephen Heppell ironically observed that educators and systems spent the 20th century perfecting the 19th century model of schooling.[10] But the pace at which things are progressing today demands a faster attention towards planning and implementation. What is also evident in this is the lack of proper training in creating decisive guiding forces. Training interventions are needed to further enthuse the incubation process and keep the momentum going. As Linda Langford has observed, literacy is in an evolving state that mirrors the changing information needs of society.[11] The new legion of learners has little time and more tasks at their disposal. To impart effective knowledge in this challenging environment is an arduous task. The need of the hour is the creation of a new cohort of educators who are ready to challenge the dynamic environment by not just being knowledge portals but innovators with ingenuity and a real sense of purpose.

These are also times of exciting opportunities. What is truly needed as a paradigm shift in pedagogy is to revamp its actual premise from teaching to sharing of knowledge while using technology as a catalytic force. Experience is most fundamental in framing the true personality of learners and the true test of an educator lies in providing the best possible experience to students to supplement their understanding of any subject. This is a possibility in every discipline area, where history can be relived and science can be created. When students see the connection between what they are learning and real world issues that matter to them, their motivation soars, and so does their learning.[12]

Education should not be restricted by what is stored in factual repositories but should be an act of 
new ideas, thoughts and actions. It is only with novelty that one can aspire for a progressive future. On one end of the paradigm lies the new media digital form of teaching and at the other end of the continuum lie such ideas as 'discovery learning' and 'constructivism', with learning perceived as an active process through which learners construct new ideas or concepts based upon their current and past knowledge.[13] A more astute observation divulges the importance of amalgamating the two notions of digitalization and imagination to create an integrated meaningful curriculum.

We need to transform curricula so that they focus less on 'things to know' and more on 'strategies for learning the things you don't know'. As new technologies continue to quicken the pace of change in all parts of our lives, learning to become a better learner is far more important than learning to multiply fractions or memorizing the capitals of the world.'[14]

\section{The new world order in technology inclusion}

The new world order demands a fundamental shift in pedagogy which takes maximum advantage of the virtual environment. Haughey, Evans and Murphy argue that technological change forces us to revisit and revise our concepts and theoretical foundations of e-education.[15] Technology offers a bouquet of opportunities for educators today. The new technological devices help the learners by ensuring flexibility. They make learning very interesting and engaging as they stimulate maximum senses of the users. Through these devices it is possible to mix education with entertainment to create 'edutainment'. These are highly motivating and provide adequate autonomy and power to the learners.[16] The spatial and temporal limitations no longer restrict the knowledge sharing process. A student is able to defy time in the quest to learn new concepts or to reinforce the pre existing knowledge. Also as a consequence of the customizable user interfaces that technology provides, learners today are able to experience a real time learning environment and create a world of endless learning at any given time and place convenient to the learner. No longer are the barriers of physical absence a constraint to the learning environment as there is abundance of opportunity to replay an event to suit the learners' needs. Marc Prensky states that, 'Today's students have mastered a large variety of tools that we will never master with the same level of skill. From computers to calculators to MP3 players to camera phones, these tools are like extensions of their brains.' [17]

The greatest impact of technology has been in actualising a social bond, persuading interactivity and interconnectivity and therefore giving a more personalised touch to the learning process. Web 2.0, or social networking software, can provide very effective ways of strengthening the impact of interpersonal learning. It can break down the sense of isolation - everything can become collaborative and social in nature. [18]

Educators have always felt constrained in dealing with learners with varied learning abilities. But new media teaching interventions allow more scope to deal with students of varied facilities in a more apt manner. Technology allows an environment of audio, visual, kinesthetic and tactile mode that makes learning a complete process. This results in a better attention span and retention. This reinforces the inclusion of technology in the compelling vision for education to come out of the vestiges of the past and make it future proof.

Educators need to articulate their teaching by being an integral part of the curriculum design process. They need to pioneer, instruction that features real world contexts and facilitates the transfer of learning from school to life.[19] This will then reduce any gap that could occur due to barriers in perception and understanding. Educators are in a sense involved in an act of deep alchemy where they have to transform lives in meaningful coherence with the dynamic world. Two major types of pedagogy that would give the necessary impetus are cooperative learning and problem based learning. Cooperative learning is a consequence of the changed world order, with collaboration becoming an imperative ingredient of our existence. Communication technology further reinforces the value of cooperation through social networking and peer bonding. Research by Jung, McConnell, and Dede and others shows that the successful integration of ICT in education can lead to the provision of learner-centred environments, access to multimediarich learning resources, expanded inter-activity, improved peer and self assessment, and responsiveness to individual needs.[20] There is a huge advantage in how the educational world operates today as it gives a lot of independence in thought and action to educators as well as learners.

Abundance of multimedia resources and an interdisciplinary content allows learners to become more versatile and prepared for change. The whole concept of a curriculum consisting of separate subjects or disciplines must certainly be challenged as students show themselves quite capable of using electronic networks to transcend old boundaries and learn in integrated ways. They become empowered to work, learn and think differently.[21] as they are exposed to a quality interactive learning experience. Problem based learning stirs the curiosity of learners and encourages brain storming and generation of novel ideas through judicious reflection. This is a much waited shift in the teaching philosophy from a pre determined robotic style to a more reality based 
powered learning environment. Personalised learning advocates the realization in learners to counter problems based on real situations and their responses. Analytical thinking, decision making, collaboration and other real time environment skills are thus honed in this process, allowing students to indulge in independent enquiry and tactful handling of situations. Problem-based learning also has been shown to increase students' active engagement with content, as well as their capacity for self-directed learning, collaboration, and social interaction. [22]

\section{Assessment to empower}

Assessment is a crucial attribute in order to ensure the impact of the educational process and to measure its effectiveness. Therefore a futuristic learning plan is incomplete without a plan for assessment. Learning objectives that are framed at the beginning of a course plan are intended to match with the learning outcomes and the assessment strategy has to coalesce acquisition of skills and application of knowledge to promote lifelong learning.

Anderson emphasises the critical role of the various forms of interaction in learning-studentstudent, student-content and student-teacher.[23] This accords with Dewey's theory that individuals' learning is a consequence of interaction between their personal (subjective) interests and experience and social (or objective) worlds[24], and Vygotsky's social constructivist thesis that interaction between people (inter-psychological) and within individual minds (intra-psychological) is fundamental to personal cognition development.[25]

Where today's education environ is acclimatizing itself till an extent in curriculum and pedagogy, assessment which is a critical defining factor to empower learners also needs to be refurbished. The assessment process has to be closely linked with the instruction process and cannot be segregated. Students need to be engaged with issues that are relevant to their lives and should be motivated to find the responses to questions themselves without the pressures of traditional testing. An active learning experience cannot be measured on a lackadaisical question answer examination. Assessments need to be intelligent and holistic in approach. From memory and recall, the testing should also shift to high order skills like collaboration, innovation, application of knowledge, solving real life problems and facing the dynamics of life. Educators need to plan assessments well and complement them with the teaching process to truly revolutionise the learning environment.

Personalised learning shall just remain a façade, if the right kind of assessments are not designed to analyze the potential of students in a holistic manner. The digital era is here to stay and we need to take maximum advantage of this while constructing the assessment strategy. Assessment needs to be flexible to cater to the autonomous learning environment of today. The tests should be exploratory in nature, enable the learner to extensively pursue new discoveries, effectively analyse the content and have an in-depth understanding of concepts to effectively apply them in real world situations. The virtual environment is a boon for innovative educators as it provides a plethora of ideas to provide the essential stimuli to enable learning.

Assessment also needs to be understood from a continuous and comprehensive indulgence of the overall abilities of learners. A given exam on a given date does not necessarily provide the complete picture of an individual's competence. In a well designed instructional environment, learning and assessment are not compartmentalized, but instead go hand in hand necessitating learner engagement on every topic. Apart from the domain knowledge that is assessed, students are assessed on their attitude and higher order thinking competencies. Formative assessments do provide an idea about the learner's progress but they need to be designed in a format that allows maximum space for abilities to be channelized and strengthened rather than deficiencies to be highlighted. Overall assessment should be focused on not just the scholastic caliber of students but on holistic development of personalities.

We need to modernise the assessment process, by utilising advances in technology and networking to generate a sense of enquiry and challenge in the minds of children. Educators need to intelligently design their assessment in a manner that it is not the speed at which a expected response is analysed but the process that leads to the discovery of new learning. Personalised learning entails that assessment should cater to the individual demands of learners and questions that are framed should be enriching, challenging and enabling to enhance varied learning abilities. The innumerable problems in education today are primarily because of the mismatch between instruction and assessment. Along with the extrinsic mode of assessment, it is also important to create a portal of self-learning for the learners of today. The assessments should be in such an inspiring way that the pursuit to find the answers becomes more stimulating than the end result.

\section{Education as a Constructive Driver}

Education has a much more important role to play in the future in defining the new world. To deliver on its potential the educational industry has to keep pace with the changing global standards and leverage on the numerous advancements. The underlying belief about the learning practice is slowly losing its ground. The age old notion on literal supremacy is being overpowered by digital explosion. It is the individual initiative and brilliance that is defining the knowledge prowess and this can be revitalized by 
providing a personalised learning environment. However the impact of the changing global scenario seeps in with least intensity in the education vertical as compared to other areas, as it is the last to accept and react to change. Most of our present educational strategies are focused on feeding and receiving information rather than innovating and finding ways and means to traverse the turbulence of the present.

Practical assumptions about the effectiveness of learning indicate the importance of social interactions in building the right learning environment. Social stimulus has become the most significant driving force in impacting learning opportunities. From face to face interactions to real time, mediated, synchronous, asynchronous settings, the learning conundrum has to adapt to the social changes. The digital cosmos revolves around social learning that allows students to study through systematic integration of media rich information. Social learning has been a unique attribute that has accentuated the cognitive ability of human beings. Now with new media interventions, a new form of social learning is emerging that allows knowledge sharing in a less formal manner and promotes interactive acquisition of ideas. Social constructivism also ensures a continuous and consistent learning curve, which is so essential to keep pace with the changing times. Where one hardly has any opportunity to think and plan the future, social learning stimulus gives the necessary impetus to gain the desired momentum to match the tempo of changing times.

Social learning environment when designed with the right technology interventions strengthens the learning potential. The learner is able to progress at his own pace and convenience and actively participate in a collaborative knowledge sharing environment. It promotes amiability and breaks prejudices and inhibitions that could hamper the learning process. Most knowledge in today's information age is captured unintentionally through social associations. A personalised learning environment is only possible if we make judicious use of each other's potential to develop a collective social intellectual power. It is important to understand that today's learners have a formidable task of not only developing their conceptual knowledge but also perfecting their interpersonal skills. The networking abilities and social intelligence has become even more important than the functional knowledge required to complete a particular task. As we foray into adopting social networking skills it is important to understand the importance of these skills in developing the holistic personality of learners.

\section{Reaching for Opportunity}

Learning new skills is important to compete and adapt. In order to venture into the workforce and be a successful professional one must be prepared with quality inputs to match learning skills with jobs. The new era will allow more opportunities for young learners and therefore we must promote access to the different forms of knowledge. We must acknowledge the real meaning of being educated is not just getting a job but also making a difference in society. We have the responsibility to create not just information 'receivers' but 'thinkers' and 'doers'. A conducive personalised learning environment helps realise the latent potential in individuals, synergise people across different locations and benefit society at large by empowering the learning process. Systematic integration of rich media is necessary as technological innovations need to be considered in context of the social and cultural contexts.

The digital generation in a highly collaborative environment has a major role to play in providing the necessary impetus to progress in society and reach maximum effectiveness. A personalised learning environment helps optimise the speed of learning and duration of engagement. If educational institutes are able to synchronise the digital stimulus with the advantages of collaboration, the personalised environment shall be effective in creating a benchmark of excellence in the field of education.

\section{Conclusion}

The education industry is not immune to the dynamism of the present. In order for education to be synonymous with excellence and quality we need to structure learning centres that recognise merit, potential and most importantly the passion to learn. Digital inputs give an additional momentum and bring life to learning. We must be optimistic in using technology and avoid having a regressive approach. At the same time, it is important to realise that we need to control the way technology is manifested in learning rather than becoming slaves to technology. Educators thus need to reboot themselves to frame curriculum that is not just a reservoir of information but a live knowledge environment. Pedagogy needs to be revisited to erode the defunct learning standards and replace them with knowledge that liberates. With novelty in creating an effective curriculum, implementing an innovative pedagogy and executing a meaningful assessment, the tribulations in the academic environment shall surely be diminished.

There is a visible shift in stylising e-content which is now no longer concentrated on information transfer software but in integrating more interesting and application based content. Differentiated teaching emerges as an important facet in creating application oriented learning that engages while it 
instructs. Research should continue to explore the critical impact of technology, collaboration and learner specific customised learning formats.

No longer is an institute of learning a dispenser of information, but a powerhouse of knowledge; the educator whose job was limited to imparting instruction has now become a transformer of resources and the content that was once limited to turning pages now ignites the intellect of learners. What would prove to be productive is to orchestrate these ideas to create edifices of personalised learning resulting in ground-breaking efforts towards meeting the challenges of education in the future.

\section{References}

[1] Fenstermacher, G.D. \& Soltis, J.F. Approaches to teaching. New York: Teachers College Press. 2004

[2]Jung, I. S. \& Rha, I. Understanding distance education. Seoul: Educational Science Publications. 2004

[3] Tucker, M.S., \& Codding, J.B. Standards for our schools: How to set them, measure them, and reach them. San Francisco: Jossey-Bass. 2002

[4] Freire, P. Pedagogy of the oppressed. New York: Continuum. 1970

[5] Perkins, D. "Integrating Thinking and Learning Skills Across the Curriculum.” In Jacobs, H. Interdisciplinary Curriculum: Design and Implementation. Alexandria, VA: Association for Supervision and Curriculum Development. 1989

[6] Toffler, Alvin. Quoted in "Wisdom Quotes: Quotations to Inspire and Challenge.”. http://www.wisdomquotes.com/001601.html.

[7] Dabbagh, N. Pedagogical models for e-learning: a theory-based design framework. International Journal of Technology in Teaching and Learning, 2005. pp 25-44.

[7] Nichols, M. (2003). A theory for e-learning. Educational Technology and Society, 6, 2. 2003,pp 1-10. Retrieved March 5, 2009, from http://www.ifets.info/others/journals/6 2/1.pdf

[7] Vrasidas, C. \& Glass, G. A conceptual framework for studying distance education. In C.Vrasidas \& G.Glass (Eds), Distance education and distributed learning, Greenwich, CT: IAP, 2002. pp. 31-56.

[8] Collins, J. Good to great and the social sectors, Random House: London, 2006, p. 15

[9] Garrison, D. R. Theoretical challenges for distance education in the 21st century: a shift from structural to transactional issues. International Review of Research in Open and Distance Learning, 1, 1. 2000

Retrieved February 22, 2009, from

http://www.irrodl.org/index.php/irrodl/article/view/2/22
[10] Heppell, S. Episode 1: Learning in the third millennium. 2005

http://connectcdn.educause.edu/files/active/0/Dublin01.mp 3

[11] Langford, Linda "Information Literacy: A Clarification.” From Now On: The Educational Technology Journal. 1998

http://optin.iserver.net/fromnow/oct98/clarify.html

[12] Bransford, J. Personal email communication with Ken Kay, President of the Partnership for 21st Century Skills, October 12, 2007.

[13] Duffy T. M. \& Jonassen D. (Eds). Constructivism and the technology of instruction: a conversation. Hillsdale, NJ: Lawrence Erlbaum Associates. 1992

[13] Bruner, J. S. Toward a theory of instruction. Cambridge Mass: Harvard University Press. 1996

[14] Resnick, M. "Rethinking learning in the digital age”, The global information technology report: Readiness for the networked world. Ed. G. Kirkman OUP, 2002. p.36

[15] Haughey, M., Evans, T. \& Murphy, D. Introduction: from correspondence to virtual learning environments. In T. D.Evans, M.Haughey \& D.Murphy (Eds), International Handbook of Distance Education. London: Emerald. 2008, pp. 1-24.

[16] Wald D.H. and A Draxler. Technologies for Education, UNESCO, Knowledge Enterprise, 2002, pp 37.

[17] Prensky, M. Listen to the Natives. Educational Leadership Vol 63 No 4 January, 2006. p.10.

[18] O'Connell, J. Engaging the Google Generation through Web 2.0: Part 1, Scan, Vol 25, No 3 August 2006.

[19] Bransford, J. Personal email communication with Ken Kay, President of the Partnership for 21st Century Skills, October 12, 2007.

[20] McConnell, D. The experience of collaborative assessment in e-learning. Studies in Continuing Education, 24, 1, 2002, pp 173-192.

[20] Dede, C. Enabling distributed learning communities via emerging technologies. THE Journal, 32, 2, 2004, pp $12-22$.

[20] Jung, I. S. Building a theoretical framework of webbased instruction. British Journal of Educational Technology, 32, 5, 2001, pp. 531-540.

[21] Caldwell, B. Re-imagining educational leadership. ACER: Melbourne. 2006

[22] Knowlton, D. "Preparing Students for Educated Living” in Knowlton, D. \& Sharp, D., eds. Problem-based Learning for the Information Age. San Francisco: Jossey Bass. 2003 
[23] Anderson, T. Getting the mix right again: an updated and theoretical rationale for interaction. International Review of Research in Open and Distance Learning, 4, 2003, p. 2.

Retrieved February 4, 2009, from

http://www.irrodl.org/index.php/irrodl/article/view/149/70 8

[24] Dewey, J. Experience and education. New York: Collier Macmillan. 1938

[25] Vygotsky, L. S. Mind in society: the development of higher psychological processes. Cambridge, MA: Harvard University Press. 1978 